\title{
3D models of buildings of the future for use in construction printing
}

\author{
Anna Zanina ${ }^{1, *}$, Olga Kitsenyuk ${ }^{1}$, Yuriy Morozov ${ }^{1}$, Andrey Dzhur ${ }^{1}$, and Ilya Serbin ${ }^{1}$ \\ ${ }^{1}$ Peter the Great St. Petersburg Polytechnic University, 29 Politechnicheskaya St., St. Petersburg, \\ 195251, Russia
}

\begin{abstract}
The article presents the development of conceptual models of buildings constructed with using Building Information Modeling software complexes. It describes the advantages and disadvantages of modern additive technologies. Features of their using are specified. Examples of their integration in modern construction are shown. Construction areas for which building models were developed were selected. The main ways of development of construction in the selected areas of activity are indicated. An analysis of current trends in the field of architecture is presented, and a forecast of future architectural trends for the coming decades based on the results provided by $3 \mathrm{D}$ Fast Build technology is made. The functional features of the buildings construction of the designated time period are taken into account. They were theoretically integrated into selected objects related to various construction areas, with their further design and modeling in the Autodesk Revit program, taking into account all identified trends and expected functionality.
\end{abstract}

\section{Introduction}

Erection of buildings using a construction 3D printer is a promising and rapidly developing area, where new results are achieved every year [1]. So, from 2009 to 2016, such innovative additive technologies as D-Shape - based on the stereolithographic printing process, Minibuilders - a system of three robotic 3D printers with a clear division of functionality, DeltaWASP-high - speed clay printing of residential buildings at an affordable price, as well as the S-1160 construction 3D printer, the Big Delta 3D printer, the ProTo R 3DP robot manipulator, the $\mathrm{CyBe} \mathrm{RC} 3 \mathrm{Dp} 3 \mathrm{D}$ printer, and the INNOprint printer are included in the construction operation [2-3].

The use of 3D printing is cost-effective [4]. A study by the Irkutsk company ApisCor confirms this. Calculating of an approximate value of prices per $1 \mathrm{~m} 2$ show that the construction of a townhouse using additive technologies is $55 \%$ more profitable than construction using traditional methods [5].

It is already possible to construct buildings entirely on the location of the $3 \mathrm{D}$ printer. Examples of such projects can be found both: abroad (Villa of Hua Shang Tengda company, China; houses of Shanghai WinSun Decoration Design Engineering company, Shanghai; "office of the future" Dubai; hotel complex, Philippines) and in national construction practice

\footnotetext{
* Correspondent author: anna.pavlenko.1996@yandex.ru
} 
(the project of a residential building of Apiscor company [6]). There is reason to believe that $3 \mathrm{D}$ printing of homes will continue to develop rapidly in the coming decades [3].

However, modern 3D printers are still limited in their capabilities. Research shows that in addition to their undeniable advantages, they have a number of disadvantages $[1-3,5,7]$. Among them:

1. The appearance of defects in the printing process due to errors in the digital model of the building;

2. Difficulties in the construction of complex architectural structures;

3. Lack of a complete regulatory and legal base for this type of construction;

4. Lack of the necessary material (concrete), which does not harden when applied to a high height and does not let the cold into the house;

5. The Dependence of construction work on the season and climatic conditions;

6. High cost of equipment associated with the lack of large series production;

7. The need for mechanical and chemical processing of parts due to rough edges and burrs.

Currently, the Russian construction company AOCG is working on creating a printer «3D

Fast Build». This is an additive hybrid technology for 3D printing that uses concrete on polymer binders with composite reinforcement of building structures of any shape without the use of formwork. The technology allows to print horizontal overhanging elements and integrate insulation into structures, which will allow to print curved structures and surfaces with reverse bending.

The purpose of this research is to develop 3D architectural models of buildings that will be used in printing on a construction printer from AOCG. Models must combine internal functionality, curved shapes (to test the printer's capabilities), and the relevance of the "3D Fast Build"technology at the time of commissioning.

Objectives of this article:

1. Analyze architectural trends for the next 5-10 years;

2. Select the most relevant areas of construction in which it is possible to use complex curved shapes;

3. Determine the type of building within the selected area and explore trends for these buildings;

4. Model architectural 3D models of buildings in the Autodesk Revit and Lumion software.

\section{Methods}

\subsection{Search and analysis of architectural styles and construction areas}

A study was conducted and several of the most relevant architectural styles were identified. They are focused on meeting the physical, aesthetic and other needs of a person. These are retrofuturism and futurism [8], bio-tech [9], eco-architecture [10-11].

Within the limits of the developed architectural style, the following areas of construction were considered: industrial, civil, administrative, and municipal [12].

Further, in these areas, various buildings were selected, which are supposed to have such technological innovations as energy efficiency, artificial intelligence, the emergence of new ways to generate energy, as well as the development of modern computer technologies, which will create a new fantastic virtual reality [13].

Special attention was paid to changes in people's needs at work [14], at school [15] or at home [16], as well as to changes in technological processes in these areas. All changes in the functionality will lead to changes in the space-planning solutions of future projects. 


\subsection{Modeling 3D model buildings}

The modeling procedure consists of the following steps:

1. Create zoning plans in AutoDesk Revit 2019. This software package was chosen because it has a number of advantages;

2. In comparison with ArchiCAD, Revit has a number of unique features that provide a higher-level product, especially if we talk about models of complex structure [17];

3. Support for third-party programs via the universal BIM format-IFC, and work with training manuals has been established [17];

4. The shaping Process in SketchUp, AutoDesk Inventor Professional, AutoDesk Revit 2019, and AutoDesk Revit 2020;

5. The creation of the final models in AutoDesk Revit 2019 and 2020;

6. Create photorealistic images of developed projects in the Lumion 9.0 program.

\section{Results}

\subsection{Long term architectural trends}

The analysis of various sources and articles by different authors substantiates the relevance and objectivity such directions as bionic architecture, sustainable architecture and neofuturism architecture. These directions reflect a lot of contemporary long term tendencies and trends, including application of green technologies, modularity and mobility of constructions and dwellings, space and property sharing, the policy of the new consumerism, etc.

\subsection{Modeling results}

The result of this research are the concepts of buildings. Their characteristics are shown in table 1 .

Table 1. Characteristics of the selected structures

\begin{tabular}{|c|l|l|}
\hline Name of the structure & \multicolumn{1}{|c|}{ Distinctive architectural features } & \multicolumn{1}{c|}{ Distinctive functional features } \\
\hline $\begin{array}{c}\text { Personal residential } \\
\text { development (cottage) }\end{array}$ & $\begin{array}{l}\text { Modularity, flexible layout, } \\
\text { multifunctionality of premises, } \\
\text { reduction of the area of technical } \\
\text { premises and the appearance of new } \\
\text { purpose zones. }\end{array}$ & $\begin{array}{l}\text { Smart home system, energy self- } \\
\text { sufficiency, built-in multifunctional } \\
\text { furniture, virtual space rooms. }\end{array}$ \\
\hline $\begin{array}{c}\text { Industrial building } \\
\text { Manufacturing zone sharing, } \\
\text { modularity, "black box" zone, tourist } \\
\text { zone, energy-efficient building shape, } \\
\text { changing the functionality and size of } \\
\text { zones for employees. }\end{array}$ & $\begin{array}{l}\text { Customization of production, minimal } \\
\text { human participation in manufacturing, } \\
\text { development of industrial tourism and } \\
\text { edutainment service, customer } \\
\text { participation in product creation. }\end{array}$ \\
\hline $\begin{array}{c}\text { Office building } \\
\text { Open-space, showroom, techno-office } \\
\text { areas, increased recreation areas, } \\
\text { flexible layouts. }\end{array}$ & $\begin{array}{l}\text { Introduction of artificial intelligence in } \\
\text { production, rooms for VR meetings, } \\
\text { interactive work, no strict division of } \\
\text { worplaces, edutainment-service. }\end{array}$ \\
\hline $\begin{array}{c}\text { Educational organization } \\
\text { (school) }\end{array}$ & $\begin{array}{l}\text { Coworking, open-space, project-room } \\
\text { areas, free layout of workspaces, no } \\
\text { standard forms. }\end{array}$ & $\begin{array}{l}\text { Introduction of project-based } \\
\text { education, creation of comfortable } \\
\text { conditions for students, destruction of } \\
\text { the hierarchical system "teacher- } \\
\text { student", multifunctionality } \\
\text { of } \\
\text { educational areas and zones. }\end{array}$ \\
\hline
\end{tabular}


The seashell shape of the scool building allows to implement a wide open-space and nonstandard layouts; the dynamism of internal spaces supports with minimizing the number of walls and partitions. There opens a new perspective with new form, changing the ordinary idea of educational process, eliminating an archaic hierarchical system, introducing projectbased education and individual approach. 3D model was performed using Autodesk Revit 2020 software program and is shown in Fig. 1.

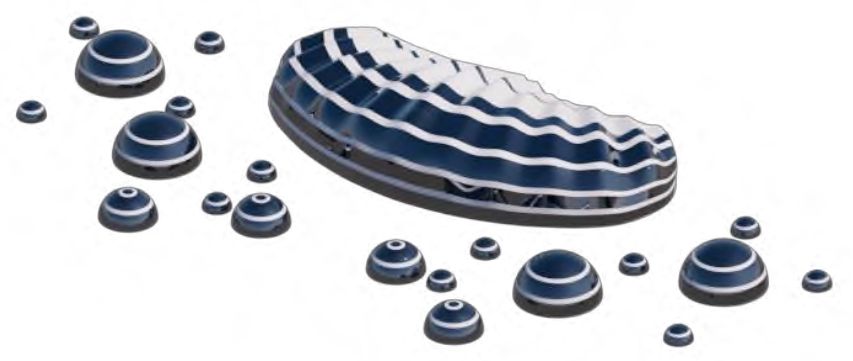

Fig. 1. 3D model of the school building

The visualization of the school building was performed in the Lumion 9.0 program is shown in Fig. 2, 3.

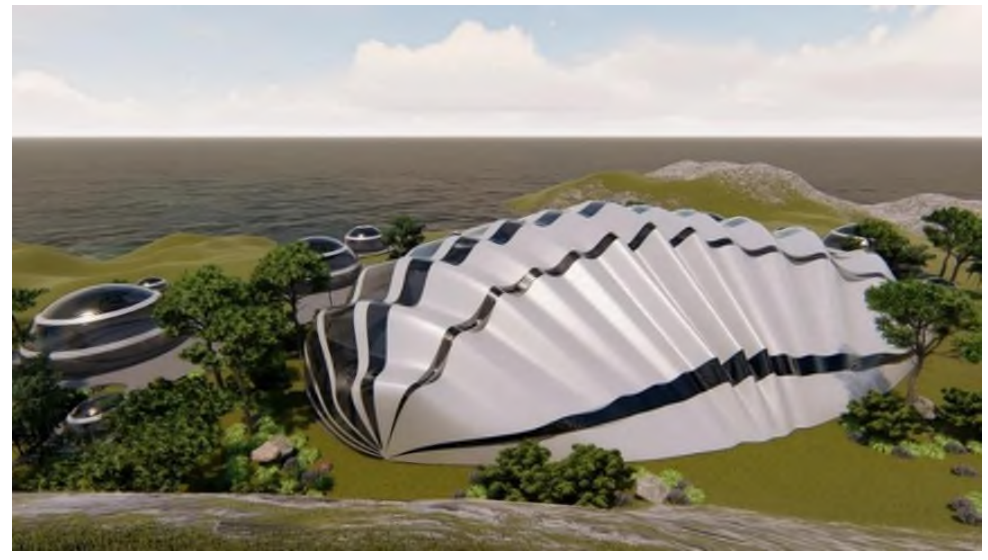

Fig. 2. Visualization of the school building

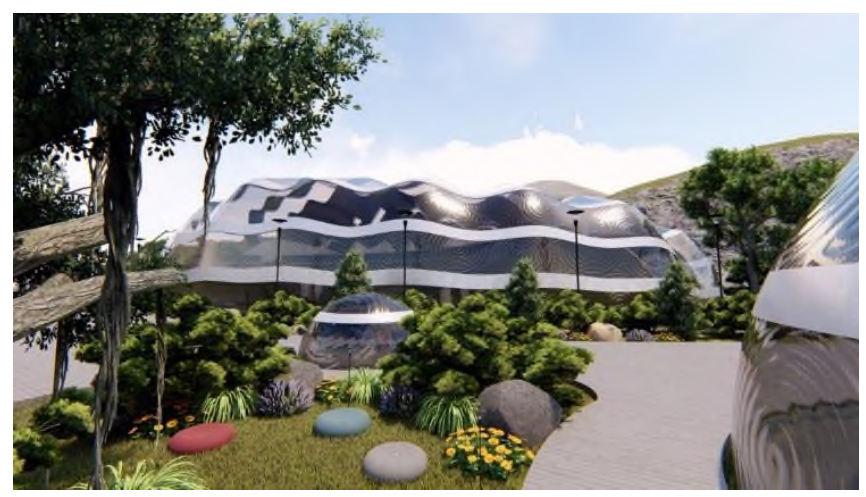

Fig. 3. Visualization of the school building 
The cottage building idea is three surging waves. This form provides efficient space usage and high functionality of the building. Communications and networks are located in the floor of the lower premises, and the new drone parking zone is combined with the technical room. 3D model was performed using Autodesk Revit 2019 software program and is shown in Fig. 4.

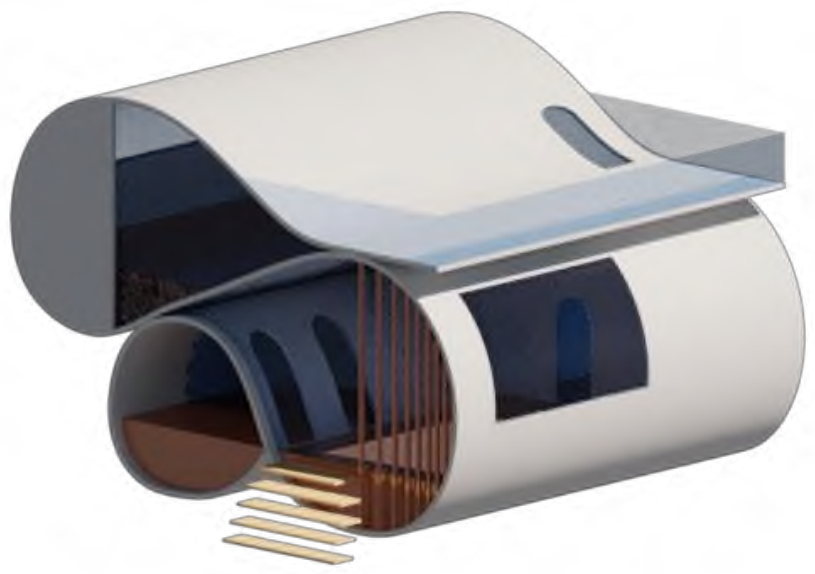

Fig. 4. 3D model of the cottage building

The visualization of the cottage building was performed in the Lumion 9.0 program is shown in Fig. 5, 6.

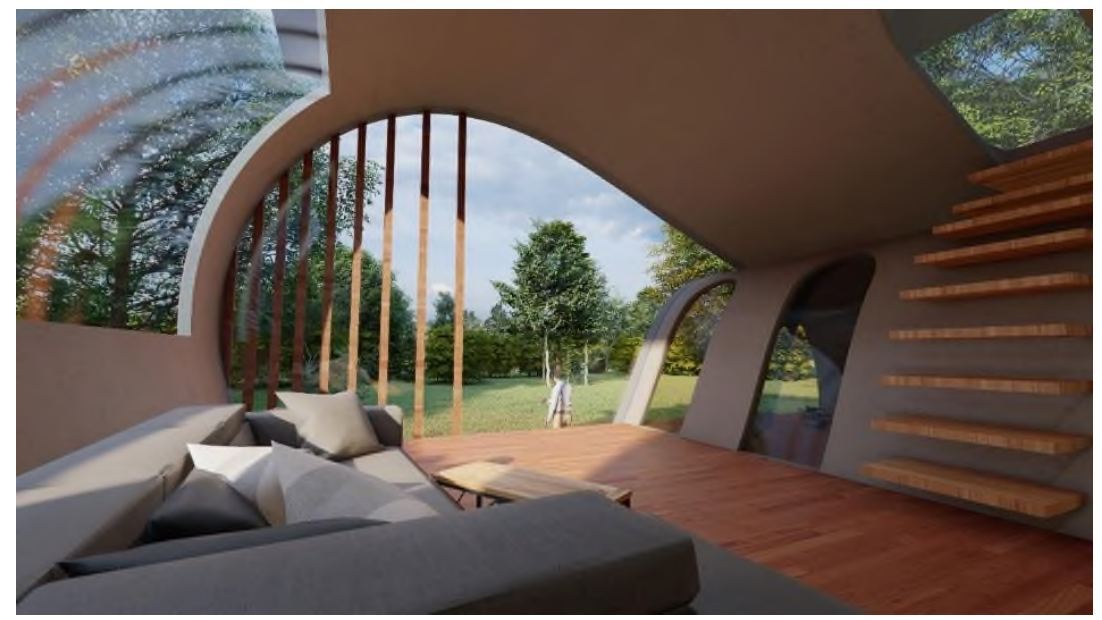

Fig. 5. Visualization of the cottage building 


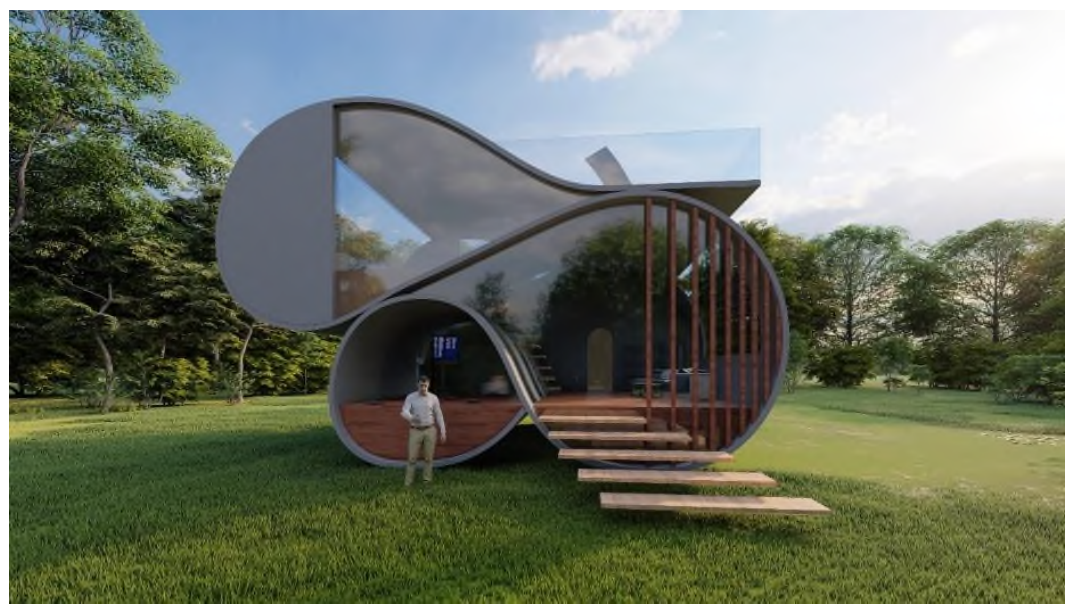

Fig. 6. Visualization of the cottage building

The office building is shaped like three whales. The internal layout is based on the openspace principle, with a minimum number of walls and with no strict zoning. Also, a lot of natural lighting is provided in the workplaces due to the large area of glazing. In turn, this solution integrates the environment into the interior of the building. 3D model of the office building was performed using Autodesk Revit 2019 software program and is shown in Fig. 7.

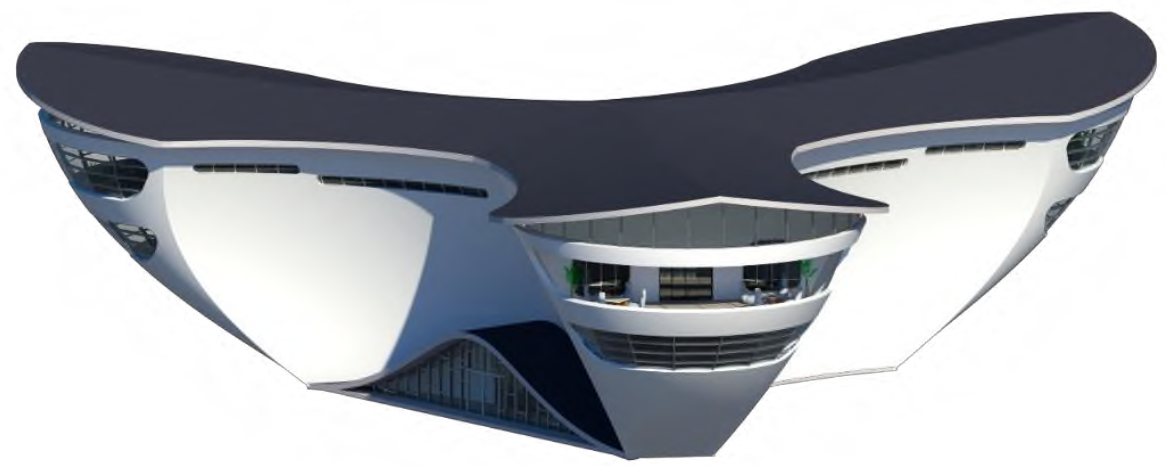

Fig. 7. 3D model of the office building

The visualization of the office building was performed in the Lumion 9.0 program is shown in Fig. 8, 9. 


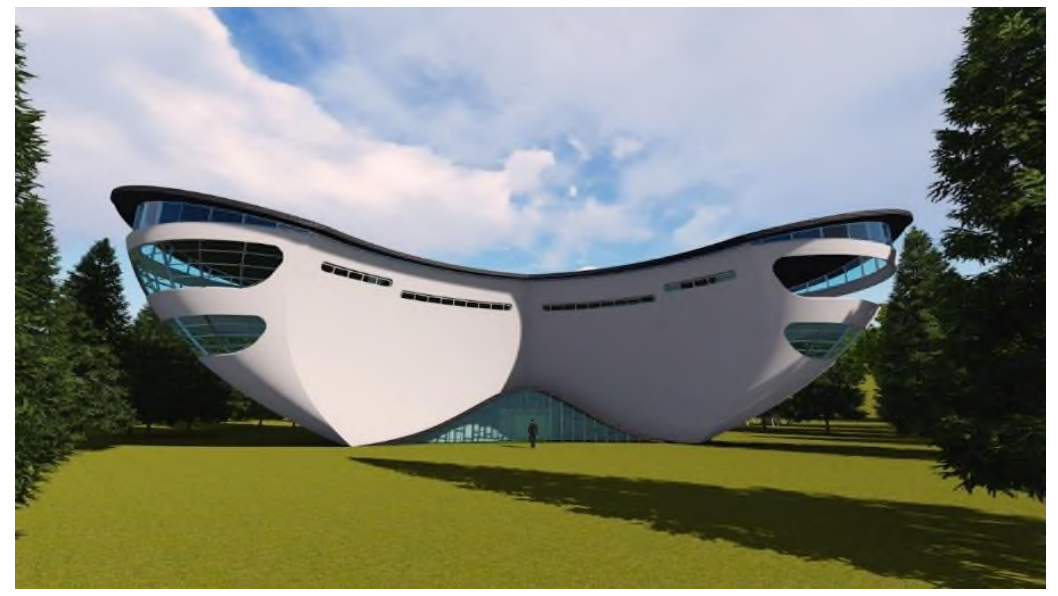

Fig. 8. Visualization of the office building

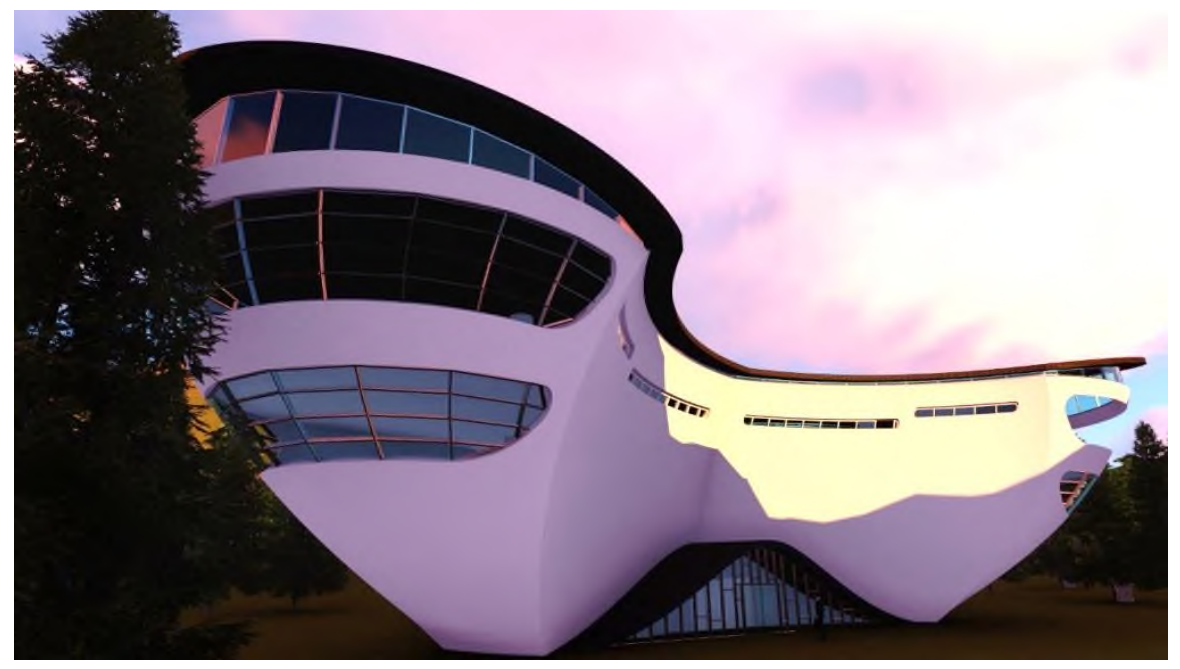

Fig. 9. Visualization of the office building

The industrial building was based on the idea of cyclicity, which is reflected in the form, zoning and energy efficiency. Consequently, the structure consists of three modular blocks in the form of turtles, which can be detached and transported to another location. Transport routes and workspaces inside the plant are connected by circular passageways. Also, there are recreation areas and interactive manufacturing zones for visitors and customers. The building is completely self-powered. 3D model of the industrial building was performed using Autodesk Revit 2019 software program and is shown in Fig. 10. 


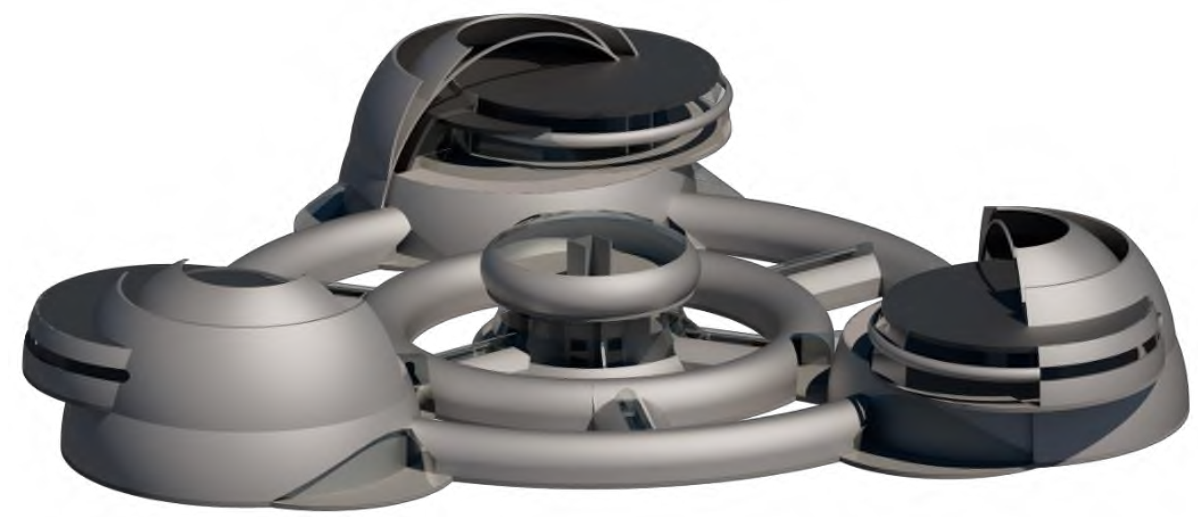

Fig. 10.3D model of the industrial building

The visualization of the industrial building was performed in the Lumion 9.0 program is shown in Fig. 11.

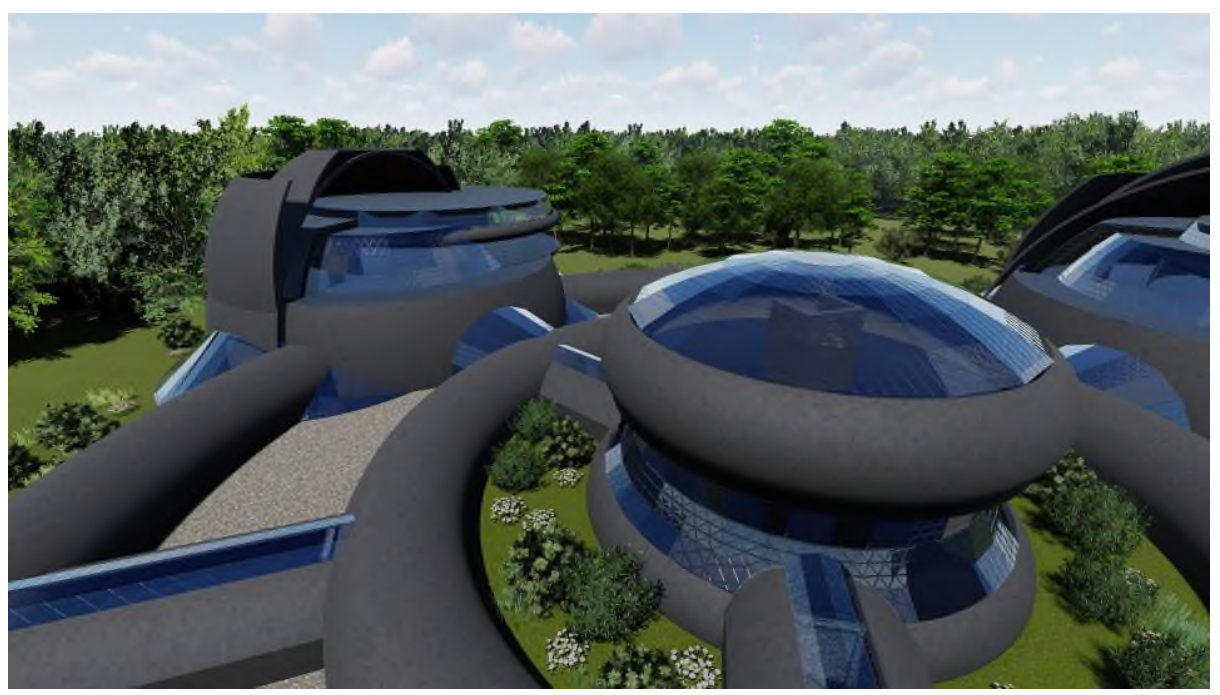

Fig. 11. Visualization of the industrial building

\section{Discussion}

The main objectives of this study was accomplished. The created projects can be used as a data source of the architectural section for design engineers and HVAC engineers. The project was created in the BIM software package Autodesk Revit, therefore, when the additive technology "3D Fast Build" comes into operation, the calculation of the volume and price of materials selected for the printer will be carried out quickly through the Revit calculation complex. The concepts can be the basis for future architectural projects shaping, and research in the field of architecture provides a clear understanding of functional and architectural changes in the selected areas of construction.

\section{Conclusions}


Additive technologies are promising way of implementing various construction processes. It possible to create complex curved shapes, using 3D printing, while using standard technological processes it is impracticable to achieve such atypical shapes. Created building concepts can fully demonstrate the potential of AOCG's 3D Fast Build printer and additive technologies in general. Usage 3D printer during construction can get buildings as comfortable as possible for people, since the convenience of the building is the focus of all subsequent construction works and planning processes. The models meet the functional and aesthetic requirements, which is a good example of top-quality design.

Also, the models correspond to those functional and architectural trends, which is inherent for future buildings. It was take into account the emergence of new departments, rooms and functional divisions that will appear in the recent years. It was designed based on a clear tendency of minimizing human participation in manufacturing and spending resources on auxiliary process, so the complete automation is set in each building.

The developed models have absorbed all the advantages that the use of additive technologies provides. In the future, they can be used to design other concepts of buildings and structures, as a basis for shaping.

\section{References}

1. W. Chen et al., Improved fire resistant performance of load bearing cold-formed steel interior and exterior wall systems. Thin-Walled Struct. Elsevier, 73, 145-157 (2013)

2. M. Terekh, D. Tretyakova, Primary energy consumption for insulating. E3S Web of Conferences, 157, 8 (2020)

3. J. Zemitis, M. Terekh, Optimization of the level of thermal insulation of enclosing structures of civil buildings, MATEC Web of Conferences, 245 (2018)

4. M.V. Gravit et al., Software packages for calculation of fire resistance of building construction, including fire protection, IOP Conference Series: Materials Science and Engineering, 456, 1 (2018)

5. M. Gravit, I. Dmitriev, Y. Lazarev, Validation of the Temperature Gradient Simulation in Steel Structures in SOFiSTiK Advances in Intelligent Systems and Computing, 983, 929-938 (2019)

6. M. V. Gravit, O. V. Nedryshkin, Full-scale tests for the simulation of fire hazards in the building with an atrium. Advances and Trends in Engineering Sciences and Technologies III-Proceedings of the 3rd International Conference on Engineering Sciences and Technologies, ESaT 2018 375-380 (2019)

7. A. Shukhardin et al., Fire simulation of light gauge steel frame wall system with foam concrete filling. Advances in Intelligent Systems and Computing, 982, 836-844 (2020)

8. N. Vatin et al., Simulation of cold-formed steel beams in global and distortional buckling. Applied Mechanics and Materials, 633-634, 1037-1041 (2014)

9. M. Garifullin et al., Buckling analysis of cold-formed c-shaped columns with new type of perforation. Advances and Trends in Engineering Sciences and Technologies Proceedings of the International Conference on Engineering Sciences and Technologies, ESaT 2015, 63-68 (2016)

10. N. Degtyareva et al., Combined bending and shear behaviour of slotted perforated steel channels: Numerical studies, J. Constr. Steel Res., 161, 369-384 (2019)

11. M. Z. Naser, N. V. Degtyareva, Temperature-induced instability in cold-formed steel beams with slotted webs subject to shear. Thin-Walled Struct, 136, 333-352 (2019) 
12. W. Chen, J. Ye, Q. Zhao, Thermal performance of non-load-bearing cold-formed steel walls under different design fire conditions. Thin-Walled Struct. Elsevier, 143, 106242 (2019)

13. W. Chen et al., Thermal behavior of external-insulated cold-formed steel non-loadbearing walls exposed to different fire conditions. Structures, 25, 631-645 (2020)

14. W. Chen et al., High-temperature steady-state experiments on G550 cold-formed steel during heating and cooling stages. Thin-Walled Struct, 151 (2020)

15. W. Chen et al., Full-scale experiments of gypsum-sheathed cavity-insulated cold-formed steel walls under different fire conditions. J. Constr. Steel Res. Elsevier, 164, 105809 (2020)

16. Y. Dias, P. Keerthan, M. Mahendran, Fire performance of steel and plasterboard sheathed non-load bearing LSF walls. Fire Saf. J., 103, 1-18 (2019)

17. S. Kesawan, M. Mahendran, Post-fire mechanical properties of cold-formed steel hollow sections. Constr. Build. Mater, 161, 26-36 (2018)

18. S. Kesawan, M. Mahendran, Fire performance of lsf walls made of hollow flange channel studs, J. Struct. Fire Eng., 8, 2 (2017)

19. W. Chen, J. Ye, X. Li, Thermal behavior of gypsum-sheathed cold-formed steel composite assemblies under fire conditions, J. Constr. Steel Res. 149, 165-179 (2018)

20. W. Chen, J. Ye, X. Li, Fire experiments of cold-formed steel non-load-bearing composite assemblies lined with different boards, J. Constr. Steel Res., 158, 290-305 (2019)

21. A. D. Ariyanayagam, S. Kesawan, M. Mahendran, Detrimental effects of plasterboard joints on the fire resistance of light gauge steel frame walls. Thin-Walled Struct, 107, 597-611 (2016)

22. T. Musorina, O. Gamayunova, M. Petrichenko, Thermal regime of enclosing structures in high-rise buildings, Vestnik MGSU, 13, 935-943 (2018)

23. T. A. Musorina, O. S. Gamayunova, M. R. Petrichenko, E. Soloveva, Boundary layer of the wall temperature field. Advances in Intelligent Systems and Computing, 1116, 429437 (2020) 